\title{
THE RELATIONSHIP BETWEEN NURSE'S JOB SATISFACTION AND MISSED NURSING CARE
}

\author{
Ilona Plevová, Renáta Zeleníková, Darja Jarošová, Eva Janíková \\ University of Ostrava, Ostrava, Czech Republic \\ Faculty of Medicine, Department of Nursing and Midwifery
}

\begin{abstract}
Background: The main aims of the study were to explore the frequency of missed nursing care (MNC) among Czech hospital nurses, and to find the relationship between nurse's job satisfaction and MNC. Material and Methods: The sample consisted of 513 nurses from 9 hospitals in the Czech Republic. Data were collected in January-August 2019 using the standardized MISSCARE Survey questionnaire, complemented with items assessing nurse's job satisfaction and demographic data. Results: The most frequently missed nursing activities were patient ambulation and emotional support to the patient and/or family. The surveyed nurses were most satisfied with being a nurse and least satisfied with the level of teamwork on their unit. The strongest correlation was found between satisfaction with the current position and satisfaction with being a nurse; there was a negative correlation between satisfaction with the current position and the overall level of MNC. There was a significant trend between the rating of satisfaction with the current position and MNC. Conclusions: Nurse's job satisfaction is associated with the level of nursing care provided; more missed care means more dissatisfaction among nurses. Med Pr. 2021;72(3):231-7
\end{abstract}

Key words: job satisfaction, nursing, nurse, hospitals, missed nursing care, MISSCARE Survey

Corresponding author: Ilona Plevová, University of Ostrava, Faculty of Medicine, Department of Nursing and Midwifery, Syllabova 19, 70300 Ostrava-Zábřeh, Czech Republic, e-mail: ilona.plevova@osu.cz

Received: June 11, 2020, accepted: January 21, 2021

\section{INTRODUCTION}

Missed nursing care (MNC) is defined as any aspect of standard, required nursing care that is not provided, including errors of omission [1]. In 2006, Kalisch et al. [2] developed a conceptual model of MNC which serves as a conceptual framework based on Donabedian's structure-process-outcome approach. The model formulates the hypothesis that hospital and unit characteristics (structural variables) lead to MNC (a process variable), in turn affecting staff (job satisfaction) and patient outcomes [3]. Various authors defined MNC as required nursing care that is not completed or is seriously delayed [4], as nursing care omitted [5], or as unfinished nursing care (also known as missed care, implicitly rationed care, and care left undone) [6]. Cho et al. [7] added that MNC also occurs when nurses must perform several simultaneous activities and cannot participate in some nursing tasks due to time constraints.
According to Jones et al. [6], the prevalence of MNC is high (55-98\%) among nursing staff in acute care hospitals internationally. It must be realized that MNS is closely associated with the issue of patient safety $[6,8-10]$. Nurses consider patient safety as one of the factors influencing their job satisfaction [11]. Vévoda et al. [12] linked job satisfaction to factors contained in Herzberg's 2-factor theory of motivation. This distinguishes between hygiene factors (work conditions, work safety, job security, salary/wages, interpersonal relationships, company policy) and motivating factors (responsibility, achievement, recognition, work itself, advancement) [12]. Excess workload results in reduced wellbeing, satisfaction and work-life balance [13]. According to Kalisch et al. [14], MNC leads to job dissatisfaction among nurses who consistently express their frustration or even feelings of despair if they cannot provide comprehensive nursing care needed by patients [14]. Frustration and stress may cause

Funding: this research was supported by INTER-COST, project No. LTC18018 entitled "Nursing care rationing as related to nurses' perceptions of professional practice environment,” project manager: Prof. Darja Jarošová, R.N., M.Sc., Ph.D. 
burnout. Among health care workers, burnout and occupational stress are increasingly considered to be important factors potentially threatening patient safety and the quality of care [15]. There is a significant relationship between MNC and job satisfaction and an intent to leave [7].

Even though Bragadóttir and Kalisch [4] claimed that MNC is a global issue, in the Czech Republic this concept is rather new to nurses who are not yet familiar with it or its meaning [16]. In addition, the relationship between MNC and nurse's job satisfaction has not been explored among Czech nurses yet.

\section{MATERIAL AND METHODS}

\section{Objectives}

The main aims of the study were to explore the frequency of MNC among Czech hospital nurses, and to find the relationship between nurse's job satisfaction and MNC.

\section{Study design}

This was a cross-sectional study.

\section{Participants and data collection}

The sample consisted of 513 nurses of non-intensive care units from 9 hospitals in the Czech Republic. From all hospitals in 1 selected Czech region, 9 agreed to participate in the survey. A voluntary response sampling method was used. The study was conducted in January-August 2019 using a paper-and-pencil questionnaire. Data were collected with the MISSCARE Survey, a standardized tool used to explore MNC. The survey [17] has 2 parts: Part A for the aspects of nursing care that are missed, and Part B for the reasons for missing care. In Part A, the respondents were asked about how often specific elements of nursing care were missed on their unit by all staff members, including themselves, using the following scale: "rarely," "occasionally," "frequently," "always" or "non-applicable." In Part B, the respondents were asked to rate each item using the following scale: "significant factor," "moderate factor," "minor factor," or "not a reason for missing nursing care" [1]. Three questions measured nurse's job satisfaction. The nurses were asked to rate their satisfaction with their current position, with being a nurse or a nurse assistant, and satisfaction with the level of teamwork on the unit using a 5-point Likert scale, from 1 - very satisfied to 5 - very dissatisfied.

\section{Statistics}

Statistical analysis was performed using the statistical software package Stata. Descriptive statistics $(\mathrm{M}, \mathrm{Me}, \mathrm{SD})$ were used to calculate demographic data while Spearman's correlation coefficient was used to test the relationship between nurse's job satisfaction and MNC. In addition, a trend test was used to explore the trend between the rating of nurse's job satisfaction and MNC.

\section{Ethical aspects}

The research protocol was approved by the Ethics Committee of the organization conducting the study (No. 1/2019, Ethics Committee, Faculty of Medicine, University of Ostrava, Czech Republic).

\section{RESULTS}

The participants were nurses $(\mathrm{N}=513)$ from 9 hospitals in the Moravian-Silesian Region of the Czech Republic. Table 1 shows the nurses' and work characteristics.

Table 1. Nurses' and work characteristics $(\mathrm{N}=513)$, in January-August 2019 in the Czech Republic

\begin{tabular}{|c|c|c|c|c|}
\hline Variable & M & SD & $\min$. & $\max$ \\
\hline Age [years] & 37.7 & 11.14 & 19 & 65 \\
\hline \multicolumn{5}{|l|}{ Working experience [years] } \\
\hline as a nurse & 14.9 & 11.11 & 0.2 & 46 \\
\hline on the current unit & 8.7 & 8.41 & 0 & 44 \\
\hline Overtime work in the past 3 months [h] & 20.7 & 23.59 & 0 & 125 \\
\hline Days or shifts of missed work due to illness, injury or extra rest in the past 3 months [n] & 1.9 & 8.03 & 0 & 90 \\
\hline Number of patients the nurse cared for on the current/last shift [n] & 14.5 & 9.63 & 0 & 40 \\
\hline Patient admissions on the current/last shift [n] & 2.6 & 2.81 & 0 & 24 \\
\hline Patient discharges on the current/last shift [n] & 2.6 & 2.77 & 0 & 20 \\
\hline
\end{tabular}


Table 2. Nurse's job satisfaction, in January-August 2019 in the Czech Republic

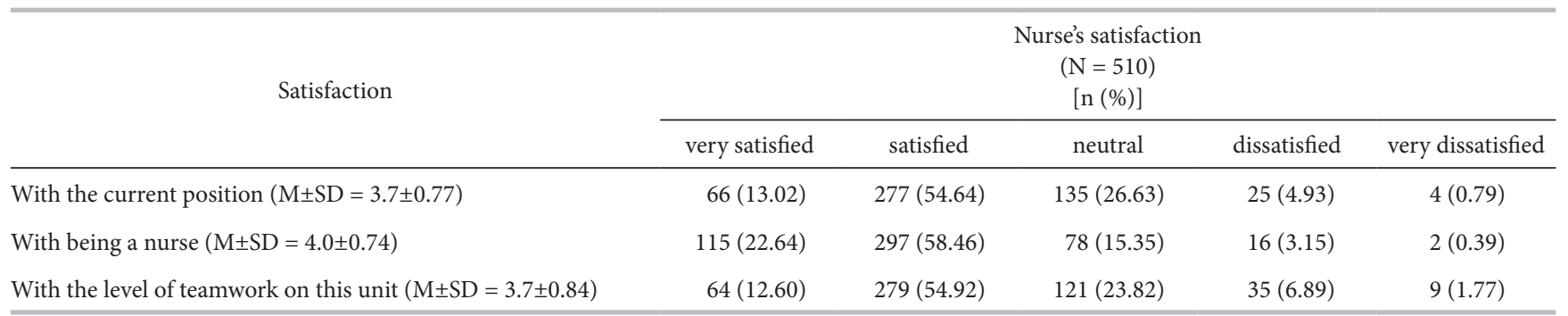

The majority of the sample were women (97\%). The participants' mean age was 37.7 years $(S D=11.14)$. The mean working experience as a nurse was 14.9 years $(\mathrm{SD}=11.11)$; the mean working experience on the current unit was 8.7 years $(\mathrm{SD}=8.41)$. Over the past 3 months, the nurses worked $20.7 \mathrm{~h}$ overtime ( $\mathrm{SD}=23.59)$. On average, each nurse missed 1.9 days of work $(\mathrm{SD}=8.03$ ) due to illness, injury or extra rest in the past 3 months. The mean number of patients the average nurse cared for on the current or last shift was $14.5(\mathrm{SD}=9.63)$, with the maximum number of patients being 40 .

As for nurse's job satisfaction, most participants were satisfied with their current position $(\mathrm{M}=3.7$, $\mathrm{SD}=0.77)$, with being a nurse $(\mathrm{M}=4.0, \mathrm{SD}=0.74)$, and with the level of teamwork on their unit $(\mathrm{M}=3.7$, $\mathrm{SD}=0.84)$. More than half of the surveyed nurses indicated "satisfied" for all 3 items. They were most satisfied with being a nurse and least satisfied with the level of teamwork on their unit (Table 2).

The most frequently missed nursing activities were ambulation 3 times per day or as ordered, emotional support to the patient and/or family, and attending interdisciplinary care conferences whenever held (Table 3 ). The least commonly missed were bedside glucose monitoring as ordered, skin/wound care, patient assessments performed each shift, and IV/central line site care and assessments according to hospital policy.

Spearman's correlation coefficient was used to determine the relationship between satisfaction with the current position, with being a nurse and with the level of teamwork on their unit (Table 4). The strongest statistically significant correlation was found between satisfaction with the current position and satisfaction with being a nurse $(p=0.4666)$. There was a statistically significant negative correlation between satisfaction with the current position and the MNC total score $(p=-0.1308)$. Even though the correlation was weak, it suggests that the nurses satisfied with their current position reported less MNC.
A trend test was used to explore the trend between the rating of nurse's job satisfaction and MNC (Table 5). There was a statistically significant trend between the rating of satisfaction with the current position and MNC $(p=0.002)$. The more satisfied the nurses were with the current position, the less MNC they reported. With increasing nurse's job satisfaction, the median MNC total score was decreasing. This trend was not shown for the rating of satisfaction with being a nurse and the MNC total score; in this case, the p-value was exactly 0.05 .

\section{DISCUSSION}

In the present study, the most frequently missed nursing activities were ambulation 3 times per day or as ordered, emotional support to the patient and/or family, and attending interdisciplinary care conferences whenever held. Studies mostly report that the most commonly missed activities are those related to basic care such as feeding, setting up meals, bathing, turning the patient [7], mouth care $[7,18,19]$, ambulation 3 times per day or as ordered $[4,13,18,19]$, and attending interdisciplinary care conferences $[7,13,19]$. Besides the differences between individual activities, some differences regarding MNC may also be seen between countries. In a comparative study on the differences between the Czech Republic and Slovakia, staff nurses in Slovakia reported more missed care than their counterparts in the Czech Republic [16]. Unfinished care is a significant problem in acute care hospitals internationally [6].

The present study also aimed to assess the relationship between nurse's job satisfaction and MNC. On their units, the participating nurses cared for as many as 40 patients. Yet Cho et al. [7] reported that nurses caring for 8-12 patients, or for $>12$ patients, were more likely to miss more activities than those caring for $<8$ patients [7]. The present study showed some considerable differences in the number of hours of overtime work in the past 
Table 3. Missed nursing care based on MISSCARE Survey [17]: frequency, in January-August 2019 in the Czech Republic

\begin{tabular}{|c|c|c|c|c|c|c|}
\hline \multirow{2}{*}{ Item } & \multicolumn{6}{|c|}{ Answers } \\
\hline & $\mathrm{n}$ & $\begin{array}{l}\text { never } \\
\text { missed } \\
{[\mathrm{n}(\%)]}\end{array}$ & $\begin{array}{l}\text { rarely } \\
\text { missed } \\
{[\mathrm{n}(\%)]}\end{array}$ & $\begin{array}{l}\text { occasionally } \\
\text { missed } \\
{[\mathrm{n}(\%)]}\end{array}$ & $\begin{array}{l}\text { frequently } \\
\text { missed } \\
{[\mathrm{n}(\%)]}\end{array}$ & $\begin{array}{l}\text { always } \\
\text { missed } \\
{[\mathrm{n}(\%)]}\end{array}$ \\
\hline "Ambulation 3 times per day or as ordered" & 510 & $47(9.2)$ & $119(23.3)$ & $151(29.6)$ & $146(28.6)$ & $47(9.2)$ \\
\hline “Turning patient every $2 \mathrm{~h}$ ” & 511 & $132(25.8)$ & $176(34.4)$ & $128(25.1)$ & $46(9.0)$ & $29(5.7)$ \\
\hline "Feeding patient when the food is still warm" & 510 & $229(44.9)$ & $158(31.0)$ & $46(9.0)$ & $35(6.9)$ & $42(8.2)$ \\
\hline "Setting up meals for patients who feed themselves" & 499 & $318(63.7)$ & $78(15.6)$ & $23(4.6)$ & $25(5.0)$ & $55(11.0)$ \\
\hline "Medications administered within 30 min before or after scheduled time" & 501 & $171(34.1)$ & $186(37.1)$ & $78(15.6)$ & $39(7.8)$ & $27(5.4)$ \\
\hline "Vital signs assessed as ordered" & 512 & $274(53.5)$ & $114(22.3)$ & $57(11.1)$ & $24(4.7)$ & $43(8.4)$ \\
\hline "Monitoring intake/output" & 512 & $269(52.5)$ & $125(24.4)$ & $52(10.1)$ & $24(4.7)$ & $42(8.2)$ \\
\hline "Full documentation of all necessary data" & 502 & $175(34.9)$ & $164(32.7)$ & $89(17.7)$ & $40(8.0)$ & $34(6.8)$ \\
\hline "Patient teaching about illness, tests, and diagnostic studies" & 502 & $158(31.5)$ & $149(30.0)$ & $105(20.9)$ & $55(11.0)$ & $35(7.0)$ \\
\hline "Emotional support to patient and/or family" & 508 & $74(14.6)$ & $150(29.5)$ & $159(31.3)$ & $103(20.3)$ & $22(4.3)$ \\
\hline "Patient bathing/skin care" & 508 & $212(41.7)$ & $165(32.5)$ & $59(11.6)$ & $37(7.3)$ & $35(6.9)$ \\
\hline "Mouth care" & 512 & $129(25.2)$ & $187(36.5)$ & $107(20.9)$ & $55(10.7)$ & $34(6.6)$ \\
\hline "Hand washing" & 503 & $229(45.5)$ & $128(25.5)$ & $51(10.1)$ & $43(8.6)$ & $52(10.3)$ \\
\hline "Patient discharge planning and teaching" & 505 & $246(48.7)$ & $127(25.2)$ & $52(10.3)$ & $42(8.3)$ & $38(7.5)$ \\
\hline "Bedside glucose monitoring as ordered" & 509 & $388(76.2)$ & $50(9.8)$ & $11(2.2)$ & $9(1.8)$ & $51(10.0)$ \\
\hline "Patient assessments performed each shift" & 512 & $322(62.9)$ & $87(17.0)$ & $31(6.1)$ & $21(4.1)$ & $51(10.0)$ \\
\hline "Focused reassessments according to patient condition" & 511 & $258(50.5)$ & $134(26.2)$ & $51(10.0)$ & $26(5.1)$ & $42(8.2)$ \\
\hline "IV/central line site care and assessments according to hospital policy" & 512 & $287(56.1)$ & $114(22.3)$ & $36(7.0)$ & $24(4.6)$ & $51(10.0)$ \\
\hline "Response to call light is initiated within 5 min" & 511 & $251(49.1)$ & $119(23.3)$ & $58(11.4)$ & $36(7.1)$ & $47(9.2)$ \\
\hline "PRN medication requests acted on within 15 min" & 510 & $190(37.3)$ & $179(35.1)$ & $65(12.8)$ & $43(8.4)$ & $33(6.5)$ \\
\hline "Assess effectiveness of medications" & 505 & $180(35.6)$ & $157(31.1)$ & $90(17.8)$ & $42(8.3)$ & $36(7.1)$ \\
\hline "Attend interdisciplinary care conferences whenever held" & 499 & $89(17.8)$ & $136(27.3)$ & $119(23.9)$ & $118(23.6)$ & $37(7.4)$ \\
\hline "Assist with toileting needs within $5 \mathrm{~min}$ of request" & 507 & $181(35.7)$ & $172(33.9)$ & $70(13.8)$ & $50(9.9)$ & $34(6.7)$ \\
\hline "Skin/wound care" & 511 & $290(56.8)$ & $136(26.6)$ & $18(3.5)$ & $26(5.1)$ & $41(8.0)$ \\
\hline
\end{tabular}

PRN - pro re nata (from Latin, meaning "as needed").

3 months. Working overtime is usually related to nurses' workplace absence, with days or shifts of missed work due to illness, injury or extra rest in the past 3 months. Long-term staff absence is a burden for the entire team. Adequate staffing is important for patient outcomes [3]. According to Cho et al. [7], a significant reason for missing care is a lack of staff, including auxiliary staff. The perception of staffing adequacy is also positively associated with job satisfaction [4]. Higher staffing levels are associated with lower rates of adverse events when caring for patients, with a patient-to-nurse ratio of 5:1 preventing complications and deaths [5].

The nurses participating in the present study were most satisfied with their current position, with being a nurse and with the level of teamwork on their unit; they were least satisfied with the level of teamwork. However, for MNC, teamwork is of key importance, with a lack of cooperation, poor communication or tension playing an important role in failing to provide adequate care. Communication tension, such as that between registered nurses and nursing assistants, has been identified as a predictive factor increasing by around half the likelihood of reporting MNC [5]. Without a clear understanding of oneself, the person's emotional reactions may adversely affect their capacity for caregiving and teamwork [20]. Nurse's job satisfaction is also directly related to increased competencies [21] and professional growth [22-24]. A lack 
Table 4. Missed nursing care and nurse's job satisfaction, in January-August 2019 in the Czech Republic

\begin{tabular}{lccc}
\hline \multicolumn{1}{c}{ Variable } & \multicolumn{2}{c}{ Spearman's correlation } \\
\cline { 2 - 3 } & 1 & 2 & 3 \\
\hline 1. Satisfaction with the current position & 1.0000 & 1.0000 & \\
2. Satisfaction with being a nurse & $0.4666^{*}$ & $0.3052^{*}$ & 1.0000 \\
3. Satisfaction with the level of teamwork on this unit & $0.4265^{*}$ & -0.0875 & -0.0688 \\
4. Missed nursing care - total score (Part A) & $-0.1308^{*}$ & 1.0000 \\
\hline
\end{tabular}

${ }^{*} \mathrm{p}<0.05$.

Table 5. Trend test between the rating of nurse's job satisfaction and missed nursing care, in January-August 2019 in the Czech Republic

\begin{tabular}{|c|c|c|c|}
\hline Nurse's job satisfaction & \multicolumn{3}{|c|}{ Missed nursing care - total score (Part A) } \\
\hline \multicolumn{4}{|c|}{ Satisfaction with the current position (trend test, $\mathrm{p}=0.002$ ) } \\
\hline 1 - very dissatisfied & 4 & 1.2 & 0.84 \\
\hline 2 - dissatisfied & 25 & 1.1 & 0.94 \\
\hline 5 - very satisfied & 66 & 0.7 & 0.96 \\
\hline \multicolumn{4}{|l|}{ Satisfaction with being a nurse (trend test, $\mathrm{p}=0.05$ ) } \\
\hline 1 - very dissatisfied & 2 & 0.9 & 0.71 \\
\hline 5 - very satisfied & 115 & 0.8 & 0.98 \\
\hline
\end{tabular}

of autonomy in decision-making and an uncertain future career are reasons for nurse's job dissatisfaction [25], with dissatisfaction with the working conditions, work atmosphere and organizational support being reported as the main reasons for leaving the nursing profession $[7,13]$. Strong nursing leadership that is respectful of nursing expertise and places patient safety foremost positively impacts on satisfaction among nurses [18].

The present study found a statistically significant trend between the rating of nurse's satisfaction with the current position and MNC. The more satisfied the nurses were with the current position, the less MNC they reported; the greater the perception of MNC on the unit, the higher the dissatisfaction level with their job [14]. Nurses' decisions about care rationing may be influenced by the organizational attributes of hospitals and their work environment [26]. The complexity of workload and care interruptions have a negative impact on job satisfaction, burnout, medication errors and patient mortality [8]. To reduce missed care and to improve patient outcomes, and thus the impact on both nurses and patients, adequate care should be provided to nurses [1,7]. For example, nurses in Magnet hospitals (i.e., those meeting a range of quality criteria defined by the American Nurses Credentialing Center) [27] reported significantly less missed care than their peers in non-Magnet hospitals [28]. Cho et al. [7] pointed to the fact that a higher number of missed activities and poorer staffing were associated with poorer patient safety, a lower quality of nursing care, lower job satisfaction, and a higher intent to leave [7].

Clear policies, organizational leadership capacity, data to drive safety improvements, skilled health care professionals and effective involvement of patients in their care are all needed to ensure sustainable and significant improvements in the safety of health care [29]. Missed nursing care influences nurse's job satisfaction, nurse-assessed quality of patient care, an intention to leave the workplace, and perceived adequacy of staffing [30]. 


\section{CONCLUSIONS}

Given the currently observed global lack of nurses, MNC is a common threat that is increasingly important as it may become, or already is, potentially dangerous. Missed care is associated with nurse's job dissatisfaction, and thus with a lower quality of care provided and a risk of adverse events. The present study has confirmed what was previously reported by many authors worldwide, but its uniqueness stems from the focus on central European nurses. Missed nursing care has a negative impact on nurse's job satisfaction.

\section{REFERENCES}

1. Kalisch BJ. Errors of omission: how missed nursing care imperils patients. Maryland: American Nurses Association; 2016.

2. Kalisch BJ. Missed nursing care: a qualitative study. J Nurs Care Qual. 2006;21(4):306-13, https://doi.org/ 10.1097/00001786-200610000-00006.

3. Kalisch BJ, Tschannen D, Lee KH. Do staffing levels predict missed nursing care? Int J Qual Healh Care. 2011;23(3):302-8, https://doi.org/10.1093/intqhc/mzr009.

4. Bragadóttir H, Kalisch BJ. Comparison of reports of missed nursing care: Registered Nurses vs. practical nurses in hospitals. Scand J Caring Sci. 2018;32(3):1227-36, https://doi.org/10.1111/scs.12570

5. Palese A, Ambrosi E, Prosperi L, Guarnier A, Barelli P, Zambiasi $\mathrm{P}$, et al. Missed nursing care and predicting factors in the Italian medical care setting. Intern Emerg Med. 2015;10(6): 693-702, https://doi.org/10.1007/s11739-015-1232-6.

6. Jones TL, Hamilton P, Murry N. Unfinished nursing care, missed care, and implicitly rationed care: State of the science review. Int J Nurs Stud. 2015;52(6):1121-37, https:// doi.org/10.1016/j.ijnurstu.2015.02.012.

7. Cho SH, Lee JY, You SJ, Song KJ, Hong KJ. Nurse staffing, nurses prioritization, missed care, quality of nursing care, and nurse outcomes. Int J Nurs Pract. 2020;26(1):e12803, https://doi.org/10.1111/ijn.12803.

8. McMullen SL, Kozik CA, Myers G, Keenan K, Wheelock M, Kalman M. Improving nursing care: examining errors of omission. Medsurg Nurs. 2017;26(1):9-15.

9. Verrall C, Abery E, Harvey C, Henderson J, Willis E, Hamilton $\mathrm{P}$, et al. Nurses and midwives perceptions of missed nursing care - a South Australian study. Collegian. 2015;22(4): 413-20, https://doi.org/10.1016/j.colegn.2014.09.001.

10. Winsett RP, Rottet K, Schmitt A, Wathen E, Wilson D. Medical surgical nurses describe missed nursing care tasks - Evaluating our work environment. Appl Nurs Res. 2016;32:128-33, https://doi.org/10.1016/j.apnr.2016. 06.006 .

11. Currey J, Sprogis SK, Orellana L, Chander A, Meagher S, Kennedy R, et al. Specialty cardiac nurses' work satisfaction is influenced by the type of coronary care unit: A mixed methods study. BMC Nurs. 2019;18:42, https:// doi.org/10.1186/s12912-019-0367-6.

12. Vévoda J, Ivanová K, Nakládalová M, Marečková J. [Work satisfaction of general nurse]. PROFESE online. 2010;3(3):207-20. Czech.

13. Holland P, Tham TL, Sheehan C, Cooper B. The impact of perceived workload on nurse satisfaction with worklife balance and intention to leave the occupation. Appl Nurs Res. 2019;49:70-6, https://doi.org/10.1016/j.apnr. 2019.06.001.

14. Kalisch BJ, Tschanen D, Lee H. Does missed nursing care predict job satisfaction? J Health Manag. 2011;56(2):11731, https://doi.org/10.1097/00115514-201103000-00007.

15. White EM, Aiken LH, McHugh MD. Registered nurse burnout, job dissatisfaction, and missed care in nursing homes. JAm GeriatrSoc. 2019;67:2065-71,https://doi.org/ 10.1111/jgs.16051.

16. Zeleníková R, Gurková E, Jarošová D. Missed nursing care measured by MISSCARE Survey - the first pilot study in the Czech Republic and Slovakia. Cent Eur J Nurs Midw. 2019;10(1):958-66, https://doi.org/10.15452/CEJNM. 2019.10.0002.

17. Kalisch BJ, Williams RA. Development and psychometric testing of a tool to measure missed nursing care. J Nurs Adm. 2009;39(5):211-19, https://doi.org/10.1097/ nna.0b013e3181a23cf5.

18. Currey J, Sprogis SK, Orellana L, Chander A, Meagher S, Kennedy R, et al. Specialty cardiac nurses' work satisfaction is influenced by the type of coronary care unit: A mixed methods study. BMC Nursing. 2019;18:42, https://doi.org/10.1186/s12912-019-0367-6.

19. Kalish BJ, Tschannen D, Lee H, Friese CR. Hospital variation in missed nursing care. Am J Med Qual. 2011;26(4): 291-9, https://doi.org/10.1177/1062860610395929.

20. Koloroutis M, editor. Relationship-Based Care. A model for transforming practice. Creative Health Care Management; 2018.

21. Bender M, Connelly CD, Brown C. Interdisciplinary collaboration: The role of the clinical nurse leader. J Nurs Manag. 2013;21(1):165-74, https://doi.org/10.1111/j.13652834.2012.01385.x.

22. Tetuan T, Browder B, Ohm R, Mosier M. The evaluation of a professional nurse contribution ladder in an integrated health care system. AAACN ViewPoint. 2013;4-9. 
23. Spiva L, Hart PL, Wesley ML, Gallagher E, McVay F, Waggoner J, et al. Psychometric testing of the clinical nurse leader staff satisfaction instrument. J Nurs Meas. 2014;22(2):302-11, https://doi.org/10.1891/1061-3749.22. 2.302 .

24. Wager KA. Assessing physician and nurse satisfaction with an ambulatory care EMR. Int J Healthc Inf Syst Inform. 2010;3(1):63-74, https://doi.org/10.4018/9781616920029. ch004.

25. Sri Hariyati T, Igarashi K, Fujinami Y, Sri Susilaningsih F, Prayenti. Correlation between career ladder, continuing professional development and nurse satisfaction: a case study in Indonesia. Int J Caring Sci. 2017;10(3):1490-7.

26. Schubert M, Glass TR, Clarke SP, Aiken LH, SchaffertWitvliet B, Sloane DM, et al. Rationing of nursing care and its relationship to patient outcomes: the Swiss extension of the International Hospital Outcomes Study. Int J Qual Health Care. 2008;20(4):227-37, https://doi. org/10.1093/intqhc/mzn017.
27. The Thruth About Nursing [Internet]. Baltimore, Maryland [cited 2019 Jan 2]. Magnet status: What it is, what it is not, and what it could be. Available from: https:// www.truthaboutnursing.org/faq/magnet.html.

28. Tubbs-Cooley HL, Pickler RH, Mara CA, Othman M, Kovacs A, MarkBA. Hospital Magnet ${ }^{\circledR}$ designation and missed nursing care in neonatal intensive care units. J Pediatr Nurs. 2017;34:5-9, https://doi.org/10.1016/j.pedn.2016. 12.004 .

29. World Health Organization [Internet]. Geneva: The Organization; 2020 [cited 2020 Apr 29]. Patient safety. Available from: https://www.who.int/patientsafety/en/.

30. Zeleníková R, Gurková E, Friganovic A, Uchmanowicz I, Jarošová D, Žiaková K, et al. Unfinished nursing care in four central European countries. 2020;28(8):1888-1900, https://doi.org/10.1111/jonm.12896.

This work is available in Open Access model and licensed under a Creative Commons Attribution-NonCommercial 3.0 Poland License - http://creativecommons.org/licenses/by-nc/3.0/pl/deed.en. 